\title{
"LA VISITA A LA CASA DE LOS TIGRES": \\ la contextualización en narrativas sobre experiencias extraordinarias
}

\author{
ESTHER JEAN LANGDON \\ Universidad Federal de SANTA Catarina \\ estherjeanbr@yahoo.com.br
}

\begin{abstract}
Resumen
Entre los indígenas siona, los vuelos chamánicos son recreados a través de la performance oral. Con el fin de explorar la relación entre la performance narrativa, la producción de la experiencia extraordinaria y la perspectiva chamánica, este trabajo analiza una narración que relata la visita a la casa de los tigres por un joven aprendiz y su chamán maestro. Este viaje al lado oculto no ocurre durante el ritual bajo la influencia del yajé, sino a la mañana siguiente, cuando el novato está de vuelta a la aldea. El análisis señala las estrategias de contextualización que permiten a la performance narrativa crear experiencias, transmitir el conocimiento chamánico e informar sobre el intercambio de perspectivas y de poder chamánico.

PALABRAS ClAVE: chamanismo, transmisión del conocimiento, contextualización, indexicalidad, performance.
\end{abstract}

\section{“Visit TO THe House of THE Jaguars": Contextualization in Narratives about EXTRAORDINARY EXPERIENCES}

\begin{abstract}
Among the Siona indians, shamanic flights and encounters in the invisible world are Arecreated through oral performance. With the objective of exploring the relation between narrative performance, the creation of extraordinary experience and shamanic perspective, the article analyzes a narrative that tells of the visit to the house of the jaguars by a young apprentice and his master-shaman. This trip to the hidden side doesn't occur during the ritual and under the influence of yajé, but in the following morning, when the novice is returning to his home. The analysis points out at the strategies of contextualization in narrative performance that work to create experience, transmit shamanic knowledge and reflect upon change of perspective and shamanic power. Keywords: shamanism, transmission of knowledge, contextualization, indexicality, performance.
\end{abstract}

Revista Colombiana de Antropología

Volumen 49 (1), enero-junio 2013, pp. 129-152 
"La visita a la casa de los tigres": la contextualización en narrativas sobre experiencias extraordinarias

\section{INTRODUCCIÓN}

ste trabajo examina una narrativa chamánica registrada en - la década del setenta entre los indígenas siona del río Putu- mayo en el sur de Colombia. Es una descripción personal de una experiencia común para los chamanes novicios en la que visitan la casa de los jaguares ubicada en el reino oculto de un universo de múltiples niveles. La narrativa es contada en el modo performativo en donde el lenguaje poético y corporal recrea hábilmente para los oyentes la experiencia vivida. El análisis aquí planteado no está tan preocupado por patrones formales poéticos y contenidos simbólicos del texto, sino enfocado en estrategias de contextualización (Bauman y Briggs 1990) que enlazan el evento de la narrativa con otros que lo preceden y lo suceden. A través de la indexicalidad y del proceso dialógico de intertextualidad (Bakhtín 1981), el evento narrativo refiere a otras experiencias con lo oculto, lo que le da una fuerza ilocucionaria capaz de transformar la experiencia y preparar a los oyentes para interpretar eventos pasados y futuros. El contexto del evento narrativo se construye a partir de sucesos anteriores y crea expectativas y significados compartidos para experiencias futuras en la cosmología chamánica.

El chamanismo, en el caso de los pueblos amerindios de las tierras bajas, es caracterizado más apropiadamente como una cosmología en la cual la mediación entre el mundo visible y lo invisible es fundamental para el bienestar de la comunidad. Se trata de un cosmos fractal, dotado de una multiplicidad de reinos y de seres animados organizados en colectividades sociales. Para los siona, las regiones invisibles se revelan a través de prácticas rituales con ingestión de yajé (Banisteriopsis sp.). Por medio de la performance ritual, los participantes experimentan de manera intensa un viaje en el mundo invisible, mientras acompañan los cantos y los movimientos del chamán. La performance ritual es el contexto para el encuentro y el diálogo con los espíritus mientras se sigue al chamán maestro en un viaje y se visitan los lugares que conoce. Varias estrategias producen una experiencia vivida extraordinaria: uso de sustancias psicotrópicas, adornos corporales, trajes especiales, dramatizaciones y diálogos cantados con los espíritus. Estas estrategias actúan juntas para producir una intensa experiencia sinestésica de transformación. El mundo 
Volumen 49 (I), enero-junio 2013

ordinario se transforma en el mundo extraordinario y el lado oculto se revela en todo su esplendor.

La experiencia con el mundo invisible no se limita a los momentos rituales. Las expresiones estéticas de los siona, a través de la ornamentación corporal, de los diseños gráficos y de las narrativas son modos performativos en los que las personas demuestran su conocimiento de otro mundo. Las performances de las narrativas que relatan las experiencias con el mundo de los espíritus constituyen una actividad común en la mañana temprano o al final del día en los grupos familiares, o entre los grupos de hombres que se entrenan para formarse como chamanes. Dicha performance es un evento interactivo en el que el narrador les cuenta a otros sus aventuras en el lado oculto del universo, y describe en detalle los pasajes en cada región que visita y los espíritus que vienen cantando, tocando y contando cómo viven.

A través del proceso de contextualización, el narrador, junto con los presentes, construye el contexto del otro mundo para referenciar el evento narrado con respecto a otros momentos y experiencias en ese otro mundo. Así, el contexto de un evento narrado no es fijo ni dado, pero emerge a través de las estrategias de indexicalidad e intertextualidad que permiten al narrador y a sus coparticipantes atravesar el espacio/tiempo del presente narrado para experimentar el otro mundo (Bauman y Briggs 1990, 69). Los contextos de otros tiempos/espacios son negociados y construidos, no por referencias simbólicas, sino por la incorporación de otros contextos en el evento narrado a través de relaciones indexicales por medio del uso de habla citada, una estrategia que incorpora hablas de otros contextos, sean estos diálogos de los sueños, los rituales u otros encuentros con los seres invisibles. Y, finalmente, el narrador provee pistas de contextualización, y ayuda a los participantes a saber cómo percibir las correspondencias entre el mundo visible y el invisible. Los acontecimientos narrados se realizan como inherentemente intertextuales, son performances de performances, que recrean las experiencias extraordinarias construidas por el ritual y por los testimonios de experiencias personales. Mecanismos poéticos, dramatizaciones corporales y vocales y estrategias de contextualización construyen la presencia del mundo invisible, y los oyentes lo experimentan junto con el narrador. La experiencia extraordinaria relatada en la performance no tiene la misma 
"La visita a la casa de los tigres": la contextualización en narrativas sobre experiencias extraordinarias

intensidad que la experiencia ritual con yajé, sin embargo, las historias son dramatizaciones poéticamente densas que enlazan el evento narrado con otros contextos de experiencias en el mundo invisible.

Una consecuencia del proceso de contextualización es la contribución de la experiencia intensificada (heightened) para la transmisión de conocimientos. Las pistas de contextualización y las relaciones indexicales en los relatos siona sobre experiencias chamánicas proporcionan la información que instruye a la audiencia sobre cómo interpretar lo que pasa en el mundo invisible, y así prepararse para los encuentros con el lado oculto, y también establecen expectativas para futuras experiencias, sean o no ocasionadas por los rituales. Con el fin de explorar la relación entre la experiencia extraordinaria, la performance y el chamanismo, este trabajo presenta una narración reportada por varios siona sobre la época de su juventud y de su aprendizaje chamánico: "La visita a la casa de los tigres". En este relato, el joven es invitado por el maestro chamán para ir a pasear a la casa de los tigres, que aparece como una casa humana en la que los tigres festejan en forma de jóvenes humanos y hermosas muchachas que lo invitan a descansar en una hamaca nueva. El maestro chamán se sienta en el rincón cerca de los tigres y explica lo que el novato está viendo. Pero este viaje al lado oculto no sucede durante el ritual bajo la influencia del yajé, sino a la mañana siguiente, cuando el novato está de vuelta a la aldea.

\section{EL CHAMANISMO Y LA TRANSMISIÓN DEL CONOCIMIENTO}

n los últimos años se han hecho importantes avances sobre la
relación entre conocimiento chamánico, poder y aprendizaje
a través de la performance, el mito y el ritual. Por un lado,
Déléage (2009, 2010) y otros analistas parten de los paradigmas
sobre memoria y antropología cognitiva para analizar la trans-
misión de conocimientos a través de los cantos rituales, con
el argumento de que dichos cantos estabilizan y transmiten la
epistemología chamánica. Por otro lado, quienes utilizan el enfo-
que de la performance examinan la eficacia ritual, y demuestran
cómo la acción ritual crea la transformación de la experiencia a 
través de procesos de sinestesia y de interacción social. Música instrumental y vocal, danza y otras técnicas trabajan en conjunto con la interacción de los participantes con fines curativos, lo cual da lugar a transformaciones mentales y corporales (Laderman y Roseman 1986; Langdon 2013).

Estas diferentes interpretaciones analíticas no están en conflicto y deben ser vistas como complementarias. Ambas aproximaciones se han traducido en avances significativos que toman en serio el conocimiento chamánico y la noción del perspectivismo en el que las apariencias están sujetas a una transformación continua, dependiendo de la perspectiva (Viveiros de Castro 1996). Las prácticas chamánicas ya no se conceptualizan como representaciones de la "magia" o las "creencias primitivas", y por lo tanto como ilusiones. Hoy en día son percibidas como manifestaciones vividas y performativas de un mundo cambiante, expresado mejor a través del concepto de perspectivismo. El chamanismo es una forma de conocimiento transmitido a través de prácticas culturales que crean la experiencia en un mundo no comprendido por la racionalidad occidental y sus principios positivistas.

Aunque la mayoría de los análisis enfocaron el poder del ritual en la creación de experiencias extraordinarias y la transmisión de la experiencia, mis investigaciones sobre el uso ritual del yajé y sobre las narrativas chamánicas han demostrado que la narración en performance tiene un papel equivalente al del rito en la comprensión de la naturaleza de los encuentros con la cara oculta de la realidad que impacta todos los aspectos de la vida cotidiana. De acuerdo con la descripción sobre los sharanahua (Déléage 2009), los chamanes iniciados narran a los chamanes novatos sus experiencias provocadas por el uso de yajé, y de esta forma los preparan para la experiencia ritual y les proporcionan los conocimientos necesarios para la mediación con la zona invisible que caracteriza la perspectiva amazónica.

Las narrativas chamánicas estructuran las expectativas de los novatos sobre la interpretación y la mediación con el lado invisible del mundo, sean estas experiencias inducidas por el consumo de sustancias, en sueños, o en encuentros repentinos en los que la persona de manera no intencional cruza la frontera entre lo visible y lo que no es visible. Las narrativas proporcionan pistas para interpretar las experiencias oníricas o rituales que se 
"La visita a la casa de los tigres": la contextualización en narrativas sobre experiencias extraordinarias

presentan como viajes a las regiones invisibles (Langdon 1979). También permiten a los chamanes novatos evitar experiencias amenazadoras y ardides provocados por los espíritus malévolos que aparecen en la selva en forma de seres humanos. En el caso de la experiencia onírica, los relatos contribuyen tanto a que la gente actúe conscientemente durante el sueño como a que pueda interpretarlos al despertar (Langdon 2004). Como se verá más adelante, las performances de las narrativas chamánicas también producen la transformación de la experiencia cotidiana en experiencia extraordinaria, no solo en momentos intensificados (heightened) que han sido ocasionados por la performance, sino también en experiencias futuras.

El enfoque sobre performance seguido hasta aquí reconoce las narraciones orales como formas literarias dinámicas que surgen de contextos específicos a través de la interacción social (Bauman 1986, 2002). Las performances crean experiencias intensificadas producidas por la capacidad del narrador para cautivar a los oyentes con la creación de las cualidades estéticas características de las actuaciones orales. La participación interactiva entre el narrador y su audiencia construye la realidad vivida (Schieffelin 1985). Las experiencias y mundos especiales se crean a través de eventos en los que los recuerdos son reelaborados como expresiones artísticas (Abrahams 1977, 81).

\section{El APRENDIZAJE CHAMÁNICO Y LAS NARRATIVAS}

os fundamentos ontológicos y epistemológicos de la cosmología chamánica siona se asemejan a los de otros grupos amazónicos -que han estado en el centro de los debates etnológicos desde los años setenta (Seeger, Da Matta y Viveiros de Castro 1987; Viveiros de Castro 1996, 2006). Es una cosmología marcada por el principio de transmutación de las formas, dependiendo del punto de vista. En este mundo transformacional, las distinciones de la racionalidad occidental —naturaleza / cultura, animal / humano, natural / sobrenatural- no operan. El cosmos está compuesto por una multiplicidad de dueños/maestros y sus comunidades sociales que se reproducen infinitamente en una lógica fractal (Kelly 2001; Cesarino 2010, 153). Esta característica de las 
entidades de transformación del universo y el cambio de punto de vista se expresa en los siona desde la perspectiva del lado (cã ${ }^{\prime} \mathrm{Co}$ ) en el que el observador se encuentra, es decir, la percepción y la experiencia tienen diferentes lados: este lado — lo visible- y el otro — el lado de las fuerzas ocultas que influyen e interfieren en los procesos de bienestar de la vida colectiva-.

Este lado es el mundo de la conciencia ordinaria, el mundo de lo que percibimos y vivimos normalmente. Contiene tres áreas principales, cada una con diferentes habitantes: la selva, el río y lo domesticado. La selva es la región de los animales. El tigre (jaguar) es la figura dominante de la selva, con todo su poder y fuerza. El río es el área de los peces y los animales acuáticos, y la anaconda es el soberano allí. En la región domesticada están los sitios de las casas y las comunidades siona, con sus animales domésticos y plantas. El chamán es el jefe que cuida a los miembros de su grupo. Estos son también conocidos como sus domesticados (hoya).

El otro lado, o región, es el dominio de los espíritus y las fuerzas invisibles que operan en espacio y tiempo no ordinarios. El cosmos está organizado en cinco niveles jerárquicos, en forma de discos planos. Los tres primeros (el inframundo, el primer cielo y el segundo cielo) son reflejos el uno del otro, en el sentido de que cada uno se divide en regiones o territorios que están habitados por pueblos diferentes. Estos grupos comparten la misma forma de socius que existe en este lado, cada uno dirigido por un amo o dueño que cuida de su pueblo. El Sol, la Luna, las Pléyades y el Trueno aparecen como las principales figuras chamánicas míticas en la esfera celeste que está más allá del alcance de los ojos: la división entre este cielo y el segundo cielo. No hay una sola palabra para clasificar a las entidades en el otro lado $\mathrm{y}$, dependiendo de la perspectiva, pueden aparecer como seres humanos (bã̃), animales (wa'i), o como wati; estos últimos son seres potencialmente malévolos, según el contexto.

Estas fuerzas personificadas afectan todos los aspectos de la existencia de este lado de la realidad. Por ejemplo, el Sol, la Gente de la Lluvia y el Trueno controlan el clima y las estaciones, y por lo tanto la producción agrícola. Todos los animales tienen un dueño, también designado como madre o padre, que determina por dónde caminan sus animales en el bosque y que negocia con el chamán cuántos de sus hijos o domesticados se liberan para ser cazados. Así que para un clima favorable para sus chagras, una 
"La visita a la casa de los tigres": la contextualización en narrativas sobre experiencias extraordinarias

buena caza o para otros fines de la vida cotidiana, es necesario ponerse en contacto y persuadir a las respectivas entidades para asegurar el bienestar en las actividades cotidianas. Sin embargo, estas entidades invisibles, sobre todo los wati, también pueden afectar la rutina habitual, causando rupturas en la forma de graves enfermedades y otras desgracias, como escasez de alimentos, accidentes, comportamientos anormales o desviados, conflictos sociales o cataclismos, tales como inundaciones o terremotos. Ciertas horas del día, así como ciertas estaciones, son periodos de gran actividad de los wati, que traen enfermedades. Por lo tanto, es peligroso bañarse en el río durante ciertas horas del día y el viento está lleno de wati que causan gripa o ampollas en la piel durante los meses secos. Una persona también puede provocar la agresión de un wati al romper un tabú o acercarse a un lugar habitado por una entidad de este tipo. Así, no se debe matar venados, ni caminar cerca de ceibas, o pasar solo cerca del cementerio. Una mujer no debe bañarse en el río durante la menstruación por temor a que su olor atraiga a un wati de agua. Los niños pequeños, especialmente los bebés, son más vulnerables a estas fuerzas invisibles. Por lo tanto, para vivir y prosperar en esta vida, para asegurar el propio bienestar, o para hacer frente a estos peligros, es necesario saber cómo vivir e interactuar con las fuerzas del otro lado.

Las actividades en el otro lado influyen sobre el desarrollo de personas, plantas, animales y fuerzas naturales, sobre las actividades de subsistencia (agricultura, caza y pesca), las relaciones intra e intercomunitarias, y los estados de salud y enfermedad. Por lo tanto, para entender los acontecimientos que quiebran el flujo de la vida social cotidiana, tales como las enfermedades u otras desgracias, es necesario entrar en el otro lado con el fin de descubrir las actividades de los seres invisibles y negociar con ellos. Los chamanes son los principales mediadores para lograr estos fines. Tienen el conocimiento suficiente para viajar en el otro lado y para negociar con las fuerzas que allí se encuentran. Ellos tienen el poder de transformación, para ponerse la "ropa" del tigre o de la anaconda, pero pueden también adoptar otras formas, tales como puercos de monte o aves. Su conocimiento y poder se desarrollan a través de un largo aprendizaje con los maestros-chamanes que les permite acumular el conocimiento necesario mediante la ingestión frecuente de yajé de forma dirigida y controlada (Langdon 1979). 
Tradicionalmente, se esperaba que todos los jóvenes adolescentes siona se comprometieran con el aprendizaje chamánico. El aprendiz comienza su formación con un chamán conocido y de confianza, por lo general un familiar, pidiéndole que "le muestre su pinta (toya)". Se prepara para el uso intensivo de yajé a través de reclusiones en la selva, dietas y otras prescripciones. Cuando está listo, el maestro comienza a darle yajé. Continúa tomando sustancias psicoactivas en contextos rituales para adquirir el conocimiento que su maestro tiene sobre los diversos dominios del universo, sus habitantes y sus cantos. A través de los rituales chamánicos, los aprendices pasan por una secuencia de pintas o experiencias en otros ámbitos del universo. El conocimiento de una pinta en particular significa que el aprendiz ha logrado seguir a su maestro al reino designado para ver a los seres que habitan allí y aprender sus cantos. Conocer una pinta implica el desarrollo de tres habilidades interrelacionadas: ver, pensar y cantar. El conocimiento chamánico exige disciplina, perseverancia y esfuerzo. Para ver una región específica y lograr el diálogo con sus seres, los siona dicen que por lo general es necesario tomar tres noches (rituales) para llegar. Algunos reinos del universo cosmológico son más difíciles de alcanzar que otros. Por ejemplo, para llegar a la Luna, con su hermosa gente flamenco, se requiere una gran cantidad de conocimientos. Un chamán iniciado me dijo que la vio "desde lejos", pero que no pudo llegar.

De este modo, el alumno pasa a través de una progresión de pintas con su maestro chamán, para conocer poco a poco los reinos del otro lado de la realidad y para aprender a hablar y negociar con sus habitantes. Experimentar una pinta significa que el aprendiz llegó al reino para ver a sus seres y escuchar sus cantos. Con cada pinta experimentada, el conocimiento chamánico crece, y esto se concibe como una sustancia que se acumula en el cuerpo del aprendiz, una sustancia delicada, que posibilita sus poderes para ver las actividades en el mundo oculto, escuchar para poder dialogar con ellos en su lengua — cada ser tiene su lenguaje propio-, y entender lo que está viendo, esto es, pensar. Estas tres capacidades en conjunto expresan el poder chamánico, el cual permite negociar con los espíritus y transformar el pensamiento en acción. Cuando el principiante puede aprender la pinta que el maestro-chamán le quería mostrar, su conocimiento chamánico se acumula. De ser un mero hombre (do '̇̇migì) pasa a convertirse en cantador (sa'isigí), y los más aptos alcanzan el 
"La visita a la casa de los tigres": la contextualización en narrativas sobre experiencias extraordinarias

nivel de maestro chamán, designado como tigre (yai), vidente (' 'łyagí) o bebedor de yajé ('úkigit). Al lograr este último nivel, el chamán finalmente tiene los conocimientos suficientes para asumir el liderazgo de los ritos y guiar a otras personas a través de las pintas en un mundo de multiplicidad infinita. Además, él tiene el poder de ponerse el vestido de tigre, o de otros seres y animales, para transformar su cuerpo durante el viaje al otro lado.

Para los siona, el rito del yajé es la principal manera de conocer a los seres del otro lado y entender el aspecto transformativo de todos los seres. Sin embargo, los sueños también proporcionan acceso al lado oculto de una manera análoga a las experiencias con yajé. Los sueños revelan además las actividades de los espíritus, las causas de la desgracia o anuncian eventos futuros. En general, el chamán es el experto en la interpretación de los sueños, pero las narrativas sobre los sueños son contadas por todo el mundo.

Por último, es posible encontrarse involuntariamente en el otro lado, cruzando la frontera que divide a esta región de las regiones liminales (en el sentido de Turner) del mundo oculto. Por lo general, estos eventos pasan cuando la persona, sola en la selva, es engañada por un espíritu malévolo; un wati aparece como un pariente o familiar y la llama a seguirlo, y le da la instrucción de cerrar los ojos. Cuando cierra los ojos, la víctima entra en el otro lado, en el reino de la nada, y se arriesga a perderse para siempre o a sufrir una enfermedad grave, si no está viendo o tomando conciencia de los peligros. Estos eventos también son relatados en narrativas en performance.

La diferencia entre las personas que realizan incursiones exitosas en el otro lado y las experiencias desafortunadas es la capacidad de mantener la conciencia, es decir, la capacidad de pensar, de no olvidar su esencia humana, de percibir el verdadero significado de la situación en la que se encuentra (Langdon 2004). Para no engañarse con las apariencias, es necesario que el individuo sea consciente de su identidad (la conciencia de que es humano) y de la perspectiva del lado en que se ubica. Si no recuerda esto, la persona se pierde, como ellos lo expresan, y el resultado es la enfermedad o la muerte. La capacidad de percibir la verdadera esencia es necesaria para la interpretación y la comprensión de lo que está sucediendo al otro lado. Todo el mundo tiene un poco de esta capacidad, principalmente porque 
todo el mundo sueña (Kracke 1987), pero para los siona, los ritos de yajé ofrecen experiencias colectivas de viajes al otro lado.

Como se ha descrito para los campa (Weiss 1973) y para los sharanahua (Déléage 2009; Siskind 1973), los ritos de yajé son una experiencia colectiva en la que los participantes acompañan la performance del chamán, cuando este viaja hasta el otro lado a través de la ingestión de yajé, se convierte en tigre, y canta y habla con los espíritus durante su visita a los otros reinos del universo. Varias estrategias ayudan a determinar las expectativas de la performance. Antes del ritual, el chamán anuncia el reino espiritual que va a ser visitado y elige qué clase de yajé debe prepararse para la pinta deseada (Langdon 1986). El conocimiento de los viajes anteriores a los reinos espirituales es parte de la cotidianidad de los siona. Los dibujos pintados en los rostros de los chamanes iniciados, en la cerámica y en otros objetos son indicios de estas experiencias en los reinos invisibles (Langdon 1992). Por último, y quizá lo más importante, las performances de las narrativas que describen las experiencias chamánicas preparan a los aprendices para lo que pueden esperar. Estas narrativas explican las correspondencias entre este lado y el lado oculto, lo cual ayuda al principiante a interpretar sus experiencias futuras. El conocimiento chamánico se trata de la capacidad de navegar por un mundo oculto de multiplicidades infinitas, que es necesario comprender e interpretar correctamente, y las narraciones chamánicas, contadas en performances, como los rituales de yajé, constituyen una parte clave en la transmisión del conocimiento.

Los temas que conforman la tradición oral siona están en su mayoría relacionados con los poderes de los chamanes o con sus actividades, posibilitadas por su conocimiento (dau) chamánico. Se cuentan historias sobre chamanes poderosos del pasado, sus ataques mágicos contra los españoles como una forma de resistencia, las enfermedades y epidemias atribuidas a ellos y otras experiencias extraordinarias, que expresan cómo el mundo invisible está relacionado con el bienestar de la gente. También se narran experiencias propias (y de otras personas) ocasionadas por ritos de yajé, y asimismo viajes oníricos que conducen al soñador a otras regiones cósmicas. Otro tema personal relatado entre ellos es el encuentro inesperado y aterrador con seres del otro lado. Estos relatos muestran cómo tales seres se manifiestan y son fuentes de conocimiento que permiten la interpretación 
"La visita a la casa de los tigres": la contextualización en narrativas sobre experiencias extraordinarias

de actividades invisibles sobre los acontecimientos cotidianos. La distinción entre mera experiencia y una experiencia, según lo sugerido por Victor Turner, permite decir que las narraciones en performance sobre las experiencias chamánicas contribuyen a nuevas vivencias. Es decir, las narrativas sobre experiencias extraordinarias con yajé no solo producen experiencias intensificadas durante el evento de sus performances, sino que también la cualidad emergente de la performance establece expectativas para las experiencias futuras con el otro lado.

Las narraciones chamánicas son expresiones estéticas y performativas (Camargo 2002) de los encuentros con la otra cara de la realidad y orientan, a través de recursos simbólicos y de contextualización, a los oyentes sobre cómo interpretar las nuevas experiencias con lo invisible. Tales recursos incluyen marcos interpretativos dentro de los cuales deben entenderse los mensajes comunicados (framing) y el lenguaje metonímico y metafórico. El uso del habla citada, para referenciar eventos previos acerca de diálogos de los espíritus, de los chamanes y otros, es una estrategia de intertextualidad que pone de relieve la experiencia y autentica la dramatización de los acontecimientos. En este sentido, la literatura oral siona es una forma de equipamiento para la vida (Burke 1957), ya que contiene instrucciones sobre cómo percibir e interpretar los acontecimientos del otro lado y poder observar las fuerzas detrás de las apariencias. Los relatos siona acerca de las experiencias extraordinarias establecen un paradigma de la realidad invisible, el cual prepara a los novatos para experimentar e interpretar las nuevas experiencias con el mundo invisible.

La narración que aquí se presenta fue relatada por Ricardo Yaigüaje, un anciano siona de aproximadamente setenta años. Ricardo era el hijo de quien fuera un poderoso chamán de la región en la primera mitad del siglo xx. Durante los años de colaboración con mi investigación, Ricardo me contó más de un centenar de historias de sus experiencias personales y también sobre las de otros chamanes, incluyendo a su padre, acerca de los encuentros con el mundo oculto. A diferencia de su padre, Ricardo no alcanzó el estatus de maestro chamán, o de tigre, debido a repetidas experiencias aterradoras durante y fuera de los rituales en los que, como consecuencia del pensamiento malévolo de otros chamanes, perdió el control de su conciencia 
y el poder de negociar con los seres invisibles, es decir, quedó incapacitado para ver, escuchar y pensar como un chamán. Pero esa es otra historia.

El relato siguiente transcurre en su tiempo de juventud, cuando aspiraba a convertirse en un chamán. Ya había comenzado a tomar yajé con su padre en la casa ritual, pero todavía no había empezado el aprendizaje formal. Esta es una experiencia de entrada al lado invisible de la selva, para visitar la casa de los tigres. Sin embargo, de acuerdo con la narrativa, este viaje tiene lugar después del ritual y no se reporta como una experiencia inducida por el rito de yajé y los cantos chamánicos. El acontecimiento narrado sucede después del rito de la mañana, cuando el aprendiz está de vuelta a la aldea. Invitado por el chamán, en un cerrar de ojos entra en el otro lado para visitar a la gente tigre en su forma humana.

Esta historia siempre me ha intrigado por que trata sobre una experiencia extraordinaria en estado de vigilia, y no en un sueño o en un rito con la ingestión de sustancias psicotrópicas. A diferencia de otros relatos sobre las experiencias inesperadas con wati, los seres malignos del bosque, su narración describe la experiencia de adquisición de conocimientos. Por otra parte, a pesar de ser una experiencia individual, en la que Ricardo demuestra la reflexividad sobre su estado de conocimiento y la capacidad de percibir los seres y sus actividades en el otro lado, visitas similares a la casa de los tigres me fueron contadas por otros chamanes iniciados.

El viaje a la casa de los tigres

NarRador: Ricardo Yaigüaje

\begin{tabular}{|c|c|}
\hline 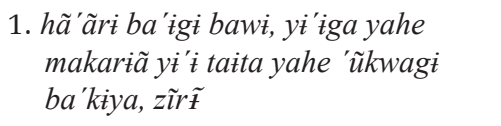 & $\begin{array}{l}\text { 1. En tiempos de mi papá, cuando } \\
\text { yo estaba pequeño, él me sirvió } \\
\text { sorbos de yajé. }\end{array}$ \\
\hline 2. ba'ihí zĩ wagi ba'ir $\tilde{t}$ & 2. Yo estaba niño en aquel tiempo \\
\hline 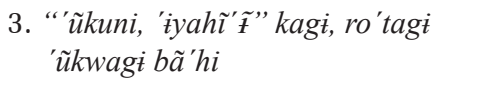 & $\begin{array}{l}\text { 3. "Beba y vea”, dijo, y pensando } \\
\text { (como chamán) me sirvió. }\end{array}$ \\
\hline 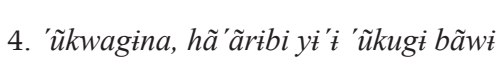 & $\begin{array}{l}\text { 4. Él me sirvió y por eso yo sabía } \\
\text { tomar. }\end{array}$ \\
\hline
\end{tabular}


"La visita a la casa de los tigres": la contextualización en narrativas sobre experiencias extraordinarias

\begin{tabular}{|c|c|}
\hline 5. 'ũkugi yua 'iragi ba'igi bawi & $\begin{array}{l}\text { 5. Yo ya era tomador cuando me } \\
\text { hice mayor. }\end{array}$ \\
\hline 6. Alfonsoru ba'igi ba'i & 6. Yo tenía como la edad de Alfonso. \\
\hline $\begin{array}{l}\text { 7. ba'igina hã'ãribi, 'ũkwani hã'ãribi } \\
\text { yahe 'ûkuni yãtawi }\end{array}$ & $\begin{array}{l}\text { 7. Y así, cuando me servían, bebía } \\
\text { yajé hasta la madrugada. }\end{array}$ \\
\hline 8. yãtani sani hã'ãr)̃te zi'zire 'ũkwewi & $\begin{array}{l}\text { 8. Una madrugada salí de la casa de } \\
\text { yajé chupando caña. }\end{array}$ \\
\hline 9. 'ükwegina, yi'ti taita sahi' $i$ & 9. Mientras esto, mi papá salió. \\
\hline 10. sani, "gere 'úkwegi yo'gine?" kagí & $\begin{array}{l}\text { 10. Salió, “¿qué es lo que está chu- } \\
\text { pando?”, preguntó. }\end{array}$ \\
\hline 11. "zi'zire 'ũkweyi, taita" & 11. "Estoy chupando caña, papá”. \\
\hline $\begin{array}{l}\text { 12. “Ah, hã 'ãka ba'ito daih } \tilde{t}^{\prime} \tilde{t} \text { 'airuna } \\
\text { sayu” kabi }\end{array}$ & $\begin{array}{l}\text { 12. "Entonces venga, vamos al mon- } \\
\text { te", me dijo él. }\end{array}$ \\
\hline 13. kani, 'airuna sabi & $\begin{array}{l}\text { 13. Así me dijo y se adentró en el } \\
\text { monte. }\end{array}$ \\
\hline 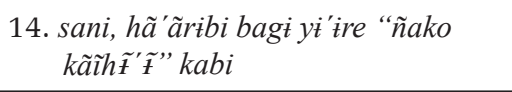 & $\begin{array}{l}\text { 14. Se adentró, y entonces me dijo: } \\
\text { "Cierre los ojos". }\end{array}$ \\
\hline 15. kagiya, yako kã̃ '́i & 15. Así me dijo y cerré los ojos. \\
\hline $\begin{array}{l}\text { 16. kã̃igina, hã'ãribi yeki de'otona } \\
\text { 'etohaihi'i }\end{array}$ & $\begin{array}{l}\text { 16. Yo los cerré y por eso apareció el } \\
\text { otro mundo. }\end{array}$ \\
\hline $\begin{array}{l}\text { 17. 'etokina, hã'arruna wi'e hobo, hai } \\
\text { hobo, wi'e hobo bahi'i }\end{array}$ & $\begin{array}{l}\text { 17. Apareció, y en aquel lugar un } \\
\text { caserío, un caserío grande había. }\end{array}$ \\
\hline $\begin{array}{l}\text { 18. ba'iruna hã ãruna, “'̃̂́ño'õ yai bã̃ } \\
\text { kì'ro" kabi }\end{array}$ & $\begin{array}{l}\text { 18. Estando en ese lugar, "este es sitio } \\
\text { de la gente jaguar", mi papá dijo. }\end{array}$ \\
\hline 19. kani, hã' ãruna tĩ'ãwi & $\begin{array}{l}\text { 19. Él hablaba y entramos en aquel } \\
\text { lugar. }\end{array}$ \\
\hline 20. tĩ'ãni wi'e bahi'i & 20. Llegamos a una casa. \\
\hline 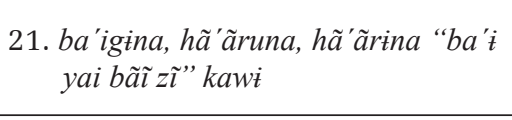 & $\begin{array}{l}\text { 21. Allá, en ese sitio, ellos dijeron: } \\
\text { "Somos los hijos de la gente } \\
\text { jaguar". }\end{array}$ \\
\hline 22. hãori, bako'a we'ma'iri bahi'i & $\begin{array}{l}\text { 22. Una hamaca, su hamaca que no } \\
\text { había sido usada. }\end{array}$ \\
\hline 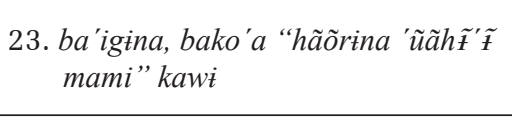 & $\begin{array}{l}\text { 23. Una hamaca limpiecita. "Acuéste- } \\
\text { se en esta hamaca muchachito", } \\
\text { me dijeron. }\end{array}$ \\
\hline 24. kahina, hã'ãrina 'ũõwi & $\begin{array}{l}\text { 24. Así me dijeron y me acosté en } \\
\text { esa hamaca. }\end{array}$ \\
\hline 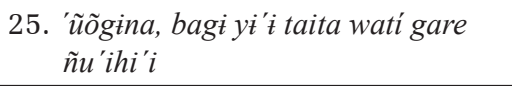 & 25. Me acosté y mi papá se sentó. \\
\hline
\end{tabular}




\begin{tabular}{|c|c|}
\hline $\begin{array}{l}\text { 26. ñu'igi hã'áribi bagì bako'a nakoni } \\
\text { koka kabi }\end{array}$ & 26. Ya sentado, él conversó con ellos. \\
\hline $\begin{array}{l}\text { 27. kagina 'tyato 'ai bã̃ ba't bã̃ yaì } \\
\text { domi gato de'ona yai domí baì'it }\end{array}$ & $\begin{array}{l}\text { 27. Él hablaba, mientras tanto vi mu- } \\
\text { chas personas, mujeres tigre, muy } \\
\text { lindas, ahí estaban las mujeres } \\
\text { tigre. }\end{array}$ \\
\hline 28. yai beto ga'wanã ye bãira bã̃ bai'ti & $\begin{array}{l}\text { 28. Con los collares de pepas de pal- } \\
\text { ma de tigre que ellas tenían. }\end{array}$ \\
\hline 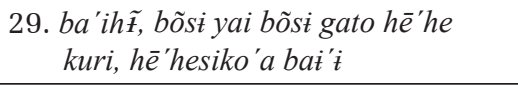 & $\begin{array}{l}\text { 29. Y los jóvenes tigre con la pintura } \\
\text { roja estaban brillando. }\end{array}$ \\
\hline $\begin{array}{l}\text { 30. he' hesikota bako'a mi'hu ba'iye } \\
\text { he'hesiko'a bai'ti }\end{array}$ & $\begin{array}{l}\text { 30. Ellos brillaban, con sus bigotes } \\
\text { pintados estaban. }\end{array}$ \\
\hline $\begin{array}{l}\text { 31. ba'iko'abi ba ko'abi hã'ã ba'iruãre } \\
\text { yai kãya detegí bã'hi tēõgwãre }\end{array}$ & $\begin{array}{l}\text { 31. Allá donde esta gente, su ropa de } \\
\text { tigre estaba colgada en las vigas } \\
\text { de la casa. }\end{array}$ \\
\hline 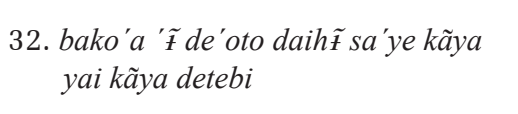 & $\begin{array}{l}\text { 32. La ropa que se ponen cuando } \\
\text { vienen para nuestro mundo, la } \\
\text { ropa de tigre estaba colgada. }\end{array}$ \\
\hline $\begin{array}{l}\text { 33. detegina, hã'ãka yai kãya se'gabi } \\
\text { yai tonogí degi ba'ihi }\end{array}$ & $\begin{array}{l}\text { 33. Estaba colgada y así la ropa de } \\
\text { tigre sola estaba colgada y gru- } \\
\text { ñendo. }\end{array}$ \\
\hline 34. degina 'íyayi & 34. Yo las veía ahí colgadas. \\
\hline $\begin{array}{l}\text { 35. 'tyagina, bako'a yai domi gato 'ai } \\
\text { ba'i gonore yo'ohr̃ ba'í bako'a }\end{array}$ & $\begin{array}{l}\text { 35. Mientras las veía, las mujeres } \\
\text { tigre estaban haciendo mucha } \\
\text { chicha. }\end{array}$ \\
\hline 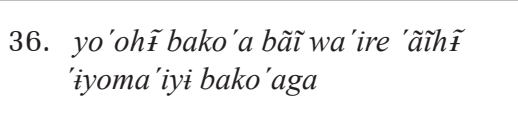 & $\begin{array}{l}\text { 36. Los vi a ellos haciendo chicha; no } \\
\text { me mostró que estaban comiendo } \\
\text { carne humana. }\end{array}$ \\
\hline 37. 'iyohina kere yi't taita yu'ihi'i & $\begin{array}{l}\text { 37. Me mostró mi papá que estaba } \\
\text { sentado más cerca. }\end{array}$ \\
\hline 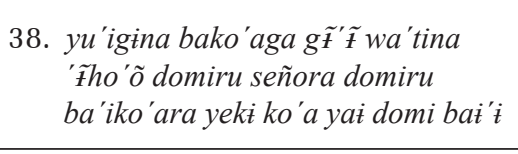 & $\begin{array}{l}\text { 38. Otras mujeres tigre tenían peines } \\
\text { en sus cabellos, así como las } \\
\text { mujeres, como las señoras de } \\
\text { este mundo. }\end{array}$ \\
\hline 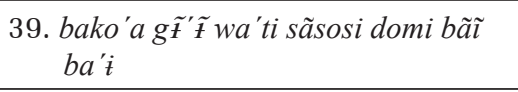 & $\begin{array}{l}\text { 39. Las mujeres tenían los peines } \\
\text { enhebrados en el cabello. }\end{array}$ \\
\hline 40. ba'ihina, "mítít'yagí mami?" kabi & $\begin{array}{l}\text { 40. Después de un rato, él me dijo: } \\
\text { “¿Estás viendo hijo?”. }\end{array}$ \\
\hline 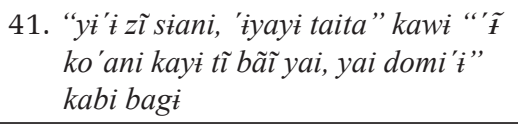 & $\begin{array}{l}\text { 41. "Sí, estoy viendo como un niño", } \\
\text { le respondí. }\end{array}$ \\
\hline 42. “'̃̃ ko'ani kayi yai bõsi'tì kabi & $\begin{array}{l}\text { 42. "Estas } \\
\text { son my }\end{array}$ \\
\hline
\end{tabular}


"La visita a la casa de los tigres": la contextualización en narrativas sobre experiencias extraordinarias

\begin{tabular}{|c|c|}
\hline $\begin{array}{l}\text { 43. gato yai bõsi gato 'ai wi'to sõ'ósi } \\
\text { ba'iko'ara bã̃ bat'i }\end{array}$ & $\begin{array}{l}\text { 43. "Aquellos son los jóvenes tigre", } \\
\text { dijo él. }\end{array}$ \\
\hline $\begin{array}{l}\text { 44. ba'iko'abi síyohei ziayãra baya } \\
\text { ho'ĩsi ba'ira bãĩ bahĩ bawi }\end{array}$ & $\begin{array}{l}\text { 44. iEran jóvenes tigre muy pintados } \\
\text { de negro con jagua! }\end{array}$ \\
\hline $\begin{array}{l}\text { 45. bako'a yeki ko'a toyasi kãyate } \\
\text { bako'a hu'i bawi }\end{array}$ & $\begin{array}{l}\text { 45. Y tenían las caras amarillas de } \\
\text { tanto aceite que se habían un- } \\
\text { tado. }\end{array}$ \\
\hline $\begin{array}{l}\text { 46. ba'iko'ata'ã 'ai de'oye koka kahr̃ } \\
\text { bawi bako'a }\end{array}$ & $\begin{array}{l}\text { 46. Otros tenían vestidos pintados } \\
\text { con dibujos. }\end{array}$ \\
\hline $\begin{array}{l}\text { 47. ba'iyeta'ã yít'iga zĩ siani do do'tagi } \\
\text { 'tyagi bawi }\end{array}$ & $\begin{array}{l}\text { 47. Aquellos estaban hablando mu- } \\
\text { chas palabras bonitas. }\end{array}$ \\
\hline $\begin{array}{l}\text { 48. 'iyagina hã'âribi “'iyani tihini } \\
\text { yurega go 'ina'a wau” kagi bawi }\end{array}$ & $\begin{array}{l}\text { 48. Ellos conversaban bien, pero yo, } \\
\text { como era un niño, me quedé } \\
\text { viéndolos sin pensar. }\end{array}$ \\
\hline 49. kani bagi go'yabi bagi & $\begin{array}{l}\text { 49. Yo estaba viendo y mi papá dijo: } \\
\text { "Ya vimos, ahora nos vamos". }\end{array}$ \\
\hline $\begin{array}{l}\text { 50. go'yani dani, "hã'ã mì't 'tyagì" } \\
\text { kabi }\end{array}$ & $\begin{array}{l}\text { 50. Él habló y recobró la conciencia. } \\
\text { Recobró la conciencia. “¿Sí vio } \\
\text { así?”, me preguntó. }\end{array}$ \\
\hline 51. "'iyawi taita" & 51. "Sí vi, papá”. \\
\hline 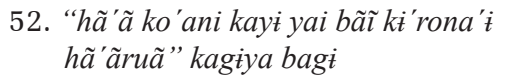 & $\begin{array}{l}\text { 52. "Allá es el sitio de la gente tigre, } \\
\text { aquel lugar", dijo él. }\end{array}$ \\
\hline $\begin{array}{l}\text { 53. kagina, "hãa'âka ba'iyi yai bãù", } \\
\text { kagi bawi yit'i }\end{array}$ & 53. "Así es la gente tigre”, me dijo él. \\
\hline 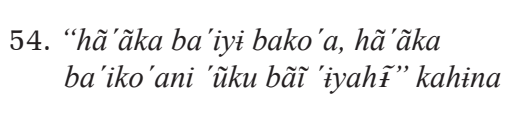 & $\begin{array}{l}\text { 54. "Así es que viven ellos. Así los } \\
\text { curacas cantan para verlos", me } \\
\text { dijo. }\end{array}$ \\
\hline 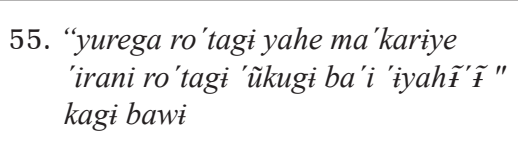 & $\begin{array}{l}\text { 55. "Hoy pensé, continúe tomando, } \\
\text { pensando y aprendiendo con } \\
\text { yajé. Vuélvase curaca y vea", él } \\
\text { dijo. }\end{array}$ \\
\hline 56. kagi yuara 'ìya daigi bawi & $\begin{array}{l}\text { 56. Así me dijo y después yo estaba } \\
\text { comenzando a ver. }\end{array}$ \\
\hline $\begin{array}{l}\text { 57. 'iyagina, yítire wacha yo'orena } \\
\text { yi'tre yure 'iyama'ki ba'igi't }\end{array}$ & $\begin{array}{l}\text { 57. Yo ya estaba viendo, pero me } \\
\text { hicieron daño y ahora ya no soy } \\
\text { curaca. }\end{array}$ \\
\hline 58. kayaye & 58. Terminé. \\
\hline
\end{tabular}


La performance de esta narrativa, a través del uso del lenguaje poético expresado en el pasado lejano, asociado a los mitos, dramatiza para la audiencia dicha experiencia en la región oculta. Además de la creación de dicha experiencia cualitativamente diferente, la performance también imparte los conocimientos necesarios para la negociación en el mundo fractal, un mundo que se caracteriza por la multiplicidad, la transformación y la diferencia de perspectivas. La performance transmite al oyente mensajes acerca de cómo ver e interpretar experiencias extraordinarias: de cómo ver la esencia de los seres y los acontecimientos. La narración no debe percibirse solo como una representación o recreación de la vida en la casa de los tigres. Las pistas de contextualización que indexan las perspectivas transforman el acto de contar en una experiencia pedagógica.

\section{Marco interpretativo (FRAME) Y METACOMUNICACIÓN}

a narración contiene un marco dentro de un marco más amplio, y ambos sirven como formas de metacomunicación que -señalan al oyente cómo debe interpretar el mensaje comunicado (Bateson 1987; Bauman 2002; Tannen y Wallet 1993). En la primera línea, el narrador anuncia que va a contar una historia verdadera acerca de su experiencia chamánica en el tiempo de su padre, quien lo estaba guiando en el aprendizaje. Ricardo crea este marco interpretativo con un tiempo verbal asociado al pasado lejano y mítico, con lo cual indica la naturaleza especial y la contextualización de conocimiento acerca de los eventos por seguir. El marco interpretativo de la narración concluye con la última línea, cuando se anuncia que terminó de contar. El segundo momento de enmarcar, de contextualizar los acontecimientos en la región oculta, se indica en las líneas 15 y 16, con las instrucciones de su padre para que cerrase los ojos, lo que señala que se ha causado la emergencia de otra región ('etohai, hacer emerger). Esto señala un cambio de registro de perspectivas para interpretar los siguientes eventos en un mundo en el que todo se muestra transformado. Los tigres aparecen como señoritas en trajes de fiesta y bebiendo chicha. El retorno desde esta región a la perspectiva ordinaria aparece en la línea 49, con la expresión que 
"La visita a la casa de los tigres": la contextualización en narrativas sobre experiencias extraordinarias

hace su padre, el guía chamánico: "Recobró la conciencia” (bagt go 'yabi). El marco interpretativo de la perspectiva en la región oculta le señala al oyente que las apariencias cambiarán y deben ser interpretadas de acuerdo con esto; los tigres tomaron cuerpos de seres humanos, con la ropa y el comportamiento que indexan sus características de existencia en este lado de las apariencias.

\section{UNIVERSO FRACTAL Y LA MULTIPLICIDAD DE PUNTOS DE VISTA}

a narración debe ser entendida como una reflexión sobre la naturaleza de las diferentes perspectivas, que no pueden concebirse como separadas por una oposición binaria extraordinario/ ordinario, resultante de la dicotomía respectiva, chamán/nochamán. La capacidad de percibir es claramente expresada como relativa y el grado de perspectiva depende del conocimiento de la persona. Las diferencias en la capacidad de ver corresponden en parte a las distintas clases de personas con capacidades chamánicas: "solo un hombre", sin el conocimiento de ver, cantador, que ya está al tanto de algunos cantos de los espíritus que ya conoce, y el vidente o tigre, que tiene la capacidad de preparar yajé y de guiar a otros en sus viajes a las regiones ocultas. Por lo tanto, estas clases de conocimiento no se refieren a capacidades homogéneas dentro de cada nivel.

El conocimiento chamánico y la capacidad de ver dependen del aprendizaje chamánico acumulado y también de la habilidad de cada uno, que, en conjunto, permiten que algunos vean más lejos y más claramente que otros. En el caso de este relato, se nos cuenta explícitamente acerca de las diferencias de perspectiva por parte de las reflexiones personales de Ricardo, del principiante que no ve tan lejos y tan claramente como su padre, quien a su vez percibe desde una posición más cercana a la gente tigre. Su padre es un vidente ( '́tyagł), que ha alcanzado el mayor nivel de conocimiento del chamanismo. En su narración, Ricardo indexa al menos tres perspectivas. La primera es la visión ordinaria que se da en la madrugada después del ritual cuando él está chupando caña inocentemente, y que ocurre luego de la visita a la casa de los tigres cuando el padre recobra su conciencia. Una vez en la otra región, con el intercambio de puntos de vista, él nos informa 
sobre su perspectiva y la de su padre: en la de él, no está viendo todo lo que su padre percibe. A través del habla citada, su padre constantemente confirma lo que está viendo. En las líneas 3537, Ricardo se refiere a una diferencia de perspectivas. Él está viendo a la gente tigre en fiesta, preparando y bebiendo chicha, mientras que su padre, desde un punto de vista más cercano, ve a los caníbales tigres comiendo carne humana. Esta diferencia entre el chamán guía y el principiante se confirma cuando, en diálogo con su padre, dice que está viendo apenas como un niño (línea 41), como una persona sin conocimiento. Esta diferencia de perspectiva - la gente tigre en fiesta, como humanos y como tigres caníbales - referencia la multiplicidad de las apariencias y perspectivas en el mundo fractal. No solo se trata de la dicotomía humano/no humano, considerando que los chamanes también se ponen vestidos de tigres para convertirse en tigres, sobre todo cuando atacan a otros en actos de brujería. Aquí tenemos una referencia, o un índice, de la posibilidad de identidades múltiples, dependiendo de la perspectiva. ¿Será que el padre de Ricardo estaba viendo un ataque chamánico?

Tras destacar los hechos como una experiencia personal, Ricardo reflexiona sobre su desarrollo en el camino para convertirse en chamán a lo largo de su aprendizaje, no solo a través de la dialogicidad y de los comentarios durante la visita a los tigres, sino también a través de la intertextualidad en las líneas finales, después del regreso a la perspectiva ordinaria y al tiempo histórico. Ricardo continuó bebiendo yajé para aprender, siguiendo las instrucciones de su padre, para escuchar y ver los cantos chamánicos (línea 54), lo que hace referencia a otros relatos que él me contó acerca de su desafortunada experiencia de haber sido embrujado (Langdon 1979, 2004), y termina con el hecho de que ya no es un curaca que puede ver debido a estos ataques.

El discurso citado de su padre, que guía a Ricardo para que sepa lo que está viendo, contiene los índices que hacen referencia a las relaciones concurrentes entre perspectivas. El conocimiento chamánico (dau), referenciado a través de los conceptos de escuchar, ver y pensar, se expresa en varias ocasiones. El aprendizaje chamánico es un proceso gradual que requiere el desarrollo de estos tres aspectos interdependientes de la conciencia. Los aprendices reciben formación a través del proceso sinestésico de la performance ritual, en la que el alumno debe dominar los 
"La visita a la casa de los tigres": la contextualización en narrativas sobre experiencias extraordinarias

tres aspectos para desarrollar adecuadamente la autonomía de su conciencia chamánica y capacitar (empower) sus intenciones para actuar en el mundo, lo que se expresa como pensar (ro 'ta-). Así, el padre de Ricardo sirve yajé pensando, Ricardo es interrogado en varias ocasiones sobre lo que está viendo, y él contesta que está viendo sin pensar. En sus últimas instrucciones, el padre aconseja a su hijo acerca de escuchar también. Escuchar bien los cantos chamánicos. Los cantos, con los efectos del yajé, se materializan en dibujos y escenas de otras regiones. Los cantos sirven para guiar a los participantes sobre cómo acompañar a los chamanes en sus pintas, de manera que contribuyen a la adquisición de conocimientos. Si no, se pueden perder en las regiones de los espíritus malévolos, y sufrir daños, enfermedades y posiblemente la muerte. Ver, escuchar y pensar referencian habilidades chamánicas a lo largo de todo el relato.

Una secuencia importante de pistas de contextualización entre perspectivas transmite informaciones sobre la correspondencia de las diferentes clases de tigres a través de descripciones de su pintura facial, su decoración corporal y de la ropa que llevan, pero son índices de los tigres en el lado cotidiano y no representaciones. De este modo, el oyente aprende a comprender las alteridades del mundo visible y la correspondencia entre perspectivas. Estos índices transmiten elementos icónicos entre las regiones visibles y ocultas del mundo fractal.

El tigre es un concepto importante en la cosmología siona. Clasificar a una persona, un animal u otro ser como tigre connota cualidades de transformación y poder. Como una clase de seres, se refiere no solo a los animales agrupados por nosotros como una familia de felinos relacionados físicamente. Como concepto, tigre se refiere a seres poderosos con hábitos depredadores. Por lo tanto, hay tigres de bosque, río y aire, todo lo que puede amenazar a alguien que está solitario en la selva o en los sueños. El tigre se asocia además con poderes chamánicos, y el maestrochamán, vidente, también es llamado tigre (yai). Asimismo, como hemos visto, el tigre tiene una forma de alteridad, y la brujería puede tomar la forma de canibalismo, según se describe en la narración (Fausto 2007). Por último, el tigre puede ser utilizado para indicar al miembro mayor de un grupo o clase de plantas, insectos o reptiles, indexando posibles y peligrosas capacidades: sapo tigre, mariposa tigre, etc. 
Durante su visita a la casa, aparecen varias clases de tigres, y esta multiplicidad es indexada por los dibujos faciales, la ropa y los adornos que referencian su apariencia en el lado de acá. Por lo tanto, los tigres jóvenes en las líneas 28 y 30 usan collares hechos de pepas de palma tigre y sus caras tienen diseños que indexan bigotes. La referencia a los dibujos faciales hechos con he' he kuri (línea 29) es un índice del color rojo brillante utilizado por la Luna, uno de los grandes chamanes ancestrales (Langdon 1995). Son los chamanes quienes en este lado, inspirados por sus experiencias con yajé, también se pintan con he’’he kuri y utilizan esos collares. Los vestidos de tigre, que ellos se "ponen" cuando vienen para la región de acá, o que el chamán utiliza cuando viaja a otra región, cuelgan de las vigas de la casa, respirando y gruñendo. A partir de la línea 37, las clases de tigres son indexadas. En las líneas 41 y 42 nos dice el chamán que las mujeres tigre con peines en la cabeza (al igual que las mujeres en esta región) son una clase diferente de la primera que apareció al llegar a la casa. El tigre negro es un hombre pintado con jagua (línea 43) y su cara está amarilla con grasa. La jagua se usó para pintarse el cuerpo en el pasado, como una marca de personas en estados especiales, y el rostro resplandeciente de grasa es apreciado estéticamente. Los tigres pintados (línea 45) se visten con ropas adornadas con dibujos, los mismos que se pintan en los rostros los chamanes para indexar su conocimiento de los espíritus, y al igual que los chamanes cantan buenas palabras. Ricardo, desde su perspectiva como aprendiz (niño), se queda apenas viendo estos tigres, sin pensar, es decir, sin aprender los cantos.

\section{Comentarios Finales}

$\int^{e}$ e acuerdo con White (1981), la narrativa es una forma de hablar sobre los eventos que convierte el saber en relato. En el caso de los siona, sus relatos privilegian el contar acerca de las visitas al otro lado de la realidad en los ritos realizados con yajé y en los sueños. Desde la perspectiva de la performance, los eventos de las narraciones no son relatos en modo indicativo, sino actos comunicativos en el modo subjuntivo (Turner 1987), con el papel formativo y transformador de la experiencia, creada a través de mecanismos estéticos, físicos y sonidos no verbales. También se convierten en experiencias pedagógicas a través de estrategias 
"La visita a la casa de los tigres": la contextualización en narrativas sobre experiencias

de contextualización que proporcionan aspectos importantes de la perspectiva del poder chamánico.

Los relatos en performance, así como los ritos, no son ilusiones (Schieffelin 1985), representaciones de un mundo imaginario o virtual (Viveiros de Castro 2006) o una forma de teatro. Como lo plantea Viveiros de Castro, no representan el mundo oculto, sino que, a través del recurso de la indexación, transmiten la realidad vivida y permiten a la audiencia interpretar las correspondencias entre el mundo ordinario y la región oculta. Las experiencias chamánicas se convierten en temas para las narraciones en performance, y las narraciones, con el proceso de contextualización, establecen relaciones indexicales entre el evento narrado y otros que lo anteceden y que lo suceden. Las narraciones sobre las experiencias de aprendizaje chamánico presentan en performance el conocimiento ganado en el camino para convertirse en chamán y lo remite a las demás personas, con lo cual contribuye a su aprendizaje.

\author{
Traducción del portugués \\ Mauricio Pardo Rojas \\ mauripardo@gmail.com
}

\title{
REFERENCIAS
}

Abrahams, Roger D. 1977. "Toward an Enactment-Centered Theory of Folklore". En Frontiers of Folklore, compilado por William R. Bascom, 79-120. Boulder: Westview Press for the American Association for the Advancement of Science.

Bakнtin, Miкhall M. 1981. The Dialogic Imagination: Four Essays by M. M. Bakhtin, editado por Michael Holquist. Austin: University of Texas Press.

Bateson, Gregory. 1987. "A Theory of Play and Fantasy". En Steps to an Ecology of Mind, 138-149. San Francisco: Chandler Publishing Company.

Bauman, Richard. 1986. Story, Performance and Event. Nueva York: Cambridge University Press.

. [1975] 2002. "El arte verbal como ejecución”. En La etnografía del habla. Textos fundacionales, compilado por Lucía Golluscio et al., 117-149. Buenos Aires: Eudeba. 
Volumen 49 (I), enero-junio 2013

Bauman, Richard y Charles Briggs. 1990. "Poetics and Performance as Critical Perspectives on Language and Social Life”. Annual Review of Anthropology 19: 59-88.

Burke, Kenneth. 1957. "Literature as Equipment for Living”. En The Philosophy of Literary Form, 253-262. Nueva York: Vintage Books.

Camargo, Eliane. 2002. "Narrativas e o modo de apreendê-las: a experiência entre os caxinauás”. Cadernos do Campo 10: 11-28.

Cesarino, Pedro de Niemeyer. 2010. "Donos e duplos: relações de conhecimento, propriedade e autoria entre Marubo”. Revista de Antropología 53 (1): 147-199.

DÉlÉAge, PierRe. 2009. "Les savoirs et leurs modes de transmission dans le chamanisme sharanahua”. Cahiers d'Anthropologie Sociale 5: 63-85. . 2010. Le chant de l'anaconda: l'apprentissage du chamanisme chez lês sharanaua. Nanterre: Societé d'ethnologie.

Fausto, Carlos. 2007. "Eating Animals and Humans in Amazonia”. Current Anthropology 48 (4): 497-530.

Kelly, José Antonio. 2001. "Fractalidade e troca de perspectivas”. Mana 7 (2): 95-132.

Kracke, Waud. 1987. "Everyone Who Dreams Has a Bit of Shaman: Cultural and Personal Meanings of Dreams. Evidence from the Amazon”. Psychiatric Journal of the University of Ottawa 12 (2): 66-72.

Laderman, Carol y Marina Roseman, comps. 1986. The Performance of Healing. Nueva York: Routledge.

Langdon, Esther Jean. 1979. "Yagé among the Siona: Cultural Patterns and Visions". En Spirits, Shamans and Stars: Perspectives from South America, compilado por David Browman y Ronald A. Schwarz, 63-82. The Hague: Mouton Publishers.

. 1986. "Las clasificaciones del yagé dentro del grupo siona: etnobotánica, etnoquímica e historia”. América Indígena 46 (1): 101-116.

. 1992. "A cultura siona e a experiência alucinogêna”. En Grafismo indígena: estudos de antropologia estética, editado por Lux Vidal, 67-87. São Paulo: Editor Nobel.

. 1995. "A morte e corpo dos xamãs nas narrativas siona”. Revista de Antropología 38 (02):107-149.

. 2004. "Shamanismo y sueños: subjetividad y representaciones de sí mismo en narrativas de sueños siona”. En Los mundos de abajo y los mundos de arriba: individuos y sociedad en las tierras bajas y los Andes. Homenaje a Gerhard Baer, compilado por María Susana Cipolletti, 26-51. Quito: Abya-Yala. 
"La visita a la casa de los tigres": la contextualización en narrativas sobre experiencias

. 2013. "La eficacia simbólica de los rituales: del ritual a la performance”. En Ayahuasca y salud, compilado por Beatriz C. Labate y José Carlos Bouso, 80-119. Barcelona: Los Libros de La Liebre de Marzo.

SCHIEFFELIN, EDWARD L. 1985. "Performance and the Cultural Construction of Reality”. American Ethnologist 12 (4): 707-724.

SeEger, Anthony, Roberto da Matta y Eduardo B. Viveiros de Castro. [1979] 1987. "A construção da pessoa nas sociedades indígenas brasileiras”. En Sociedades indígenas e indigenismo no Brasil, compilado por João Pacheco de Oliveira Filho, 11-30. Río de Janeiro: UFRJ / Editora Marco Zero.

Siskind, JAnet. 1973. To Hunt in the Morning. Nueva York: Oxford University Press.

Tannen, Deborah y Cynthia Wallat. 1993. "Interactive Frames and Knowledge Schemas in Interaction: Examples from a Medical Examination/ Interview”. En Framing in Discourse, editado por D. Tannen, 57-76. Nueva York: Oxford University Press.

Turner, Victor. 1987. The Anthropology of Performance. Nueva York: PAJ Publications.

Viveiros de Castro, Eduardo B. 1996. “Os pronomes cosmológicos e o perspectivismo ameríndio”. Mana 2 (2): 115-144.

. 2006. "A floresta de cristal: notas sobre a ontologia dos espiritos amazônicos”. Cadernos de Campo 14-15: 319-338.

Weiss, Gerald. 1973. "Shamanism and Priesthood in Light of the Campa Ayahuasca Ceremony”. En Hallucinogens and Shamanism, compilado por Michael Harner, 40-47. Nueva York: Oxford University Press.

White, Hayden. 1981. "The Value of Narrativity in the Representation of Reality”. En On Narrative, compilado por W. J. T. Mitchell, 1-24. Chicago: University of Chicago Press. 